\title{
FGFR1 Gene Rearrangement
}

National Cancer Institute

\section{Source}

National Cancer Institute. FGFR1 Gene Rearrangement. NCI Thesaurus. Code C84273.

Rearrangement of the FGFR1 gene resulting in translocations with an 8p11 breakpoint. It has been described in hematologic malignancies presenting as myeloproliferative neoplasms or acute leukemias. 